\title{
Intentional vocabulary learning via WhatsApp: Does the type of input matter?
}

\author{
Mojgan Rashtchi ${ }^{\mathrm{a}, 1,{ }^{*}}$, Parisa Yazdani ${ }^{\mathrm{b}, 2}$ \\ a Islamic Azad University, North Tehran Branch, Islamic Republic of Iran, \\ b TEFL Department, Faculty of Foreign Languages, North Tehran Branch, Islamic Azad University, Tehran, Islamic Republic of Iran \\ ${ }^{1}$ mojgan.rashtchi@gmail.com* ; ${ }^{2}$ parisa_yz@yahoo.com \\ * corresponding author
}

ARTICLE INFO

Article history

Received 09 July 2020

Revised 29 July 2020

Accepted 30 August 2020

Keywords

input modality

learning

social networking

WhatsApp

\section{ABSTRACT}

Nowadays, vocabulary as an influential domain in mastering second/foreign languages has encouraged researchers to put forth conceptualizations that can substantiate the successful learning of words. This study used WhatsApp to investigate the different impacts of two input modalities (voice messages vs. written texts) on EFL learners' intentional learning and retention of words. To this end, 50 female EFL learners in two intact classes $(n 1=n 2=25)$ were selected from a language institute in Khorramabad, Iran. The groups were randomly assigned to two treatment conditions. The results of a general English proficiency test verified their homogeneity at the outset. A standardized teacher-made vocabulary test assured the researchers that the words were unfamiliar to the learners. After the twelve-session treatment, which was integrated with conventional English teaching classes, another standardized vocabulary test was administered once immediately after the intervention and the second time after a two-week interval. The Friedman repeated measures analysis showed a significant difference between the pretest and posttests. However, the results of the statistical analyses showed no statistically significant differences between the participants' performances on the immediate and delayed posttests. Thus, the researchers concluded that the participants had not forgotten the words from the first to the second posttest indicating the efficacy of intentional vocabulary learning. Additionally, no significant differences were found between the two groups showing the similar impacts of the input modality. The study has implications for EFL teachers and educators whose focus is on TEFL.

口if This is an open access article under the CC-BY-SA license.

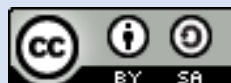

\section{Introduction}

Second language vocabulary acquisition, as a discrete domain of study, has stimulated numerous investigations and has contributed to SLA researchers' understanding of the factors that affect the process of learning. According to Cohen and Weaver (2005), vocabulary learning has a significant role in the improvement of four language skills and can contribute to gaining communicative competence. A challenging task language learners face is how to retain the vocabulary they have learned. Focus on the features of new words, contextual/ decontextualized learning, frequency of encounters, and noticing are factors that determine the degree of success in vocabulary learning (Pellicer-Sánchez, 2020). For retention of vocabulary, as Nation and Gu (2007) argue, memory, processing, storing, and using L2 words in productive ways can play decisive roles. Pyc and Rawson (2009) believe that deep processing of words in the cognitive framework of learners leads to more successful retention. Craik and Lockhart's (1972) Information Processing Model explains that the level of processing is a determining factor in the storage of data in memory. 
The theories regarding working memory can also explain vocabulary retention. As a cognitive information storage processing system, working memory can facilitate the retention and utilization of information (Baddeley, 1997). However, as proposed by Baddeley (1986), working memory has a limited capacity, and the presentation of data via a single channel splits its function, and thus imposes a high cognitive load on it and can have a detrimental role in the process of learning (Sweller \&Chandler, 1994). Therefore, a balance in the presentation of learning materials contributes to the efficiency of using the limited working memory capacity and decreases cognitive load (Baddeley, 1992). Second language learners need to store information and engage in cognitive processing to transfer the target language to long-term memory, which is called the process of language retention (Baddeley \& Hitch, 1974). As a result, employing a combination of input modalities is superior to a single modality input as small amounts of information are stored in two different paths or loops. According to the modality principle (Atkinson, 2005; Mayer, 2009), employing different instructional formats (Paas, van Gog, \& Sweller, 2010) can lead to successful retention. By using different types of input, learners can retain and utilize the information they need to accomplish tasks that require reasoning and comprehension (Baddeley, 1986).

Thus, teachers' responsibility is to help learners successfully store and retrieve words by employing effective pedagogical methods in teaching. One way to do so is through the use of technology and social media in the classroom. By infusion of technology into EFL classes, teachers can provide learners with the condition of dual contexts for learning vocabulary and expose them to a large amount of input (Blake, 2008). Researchers of the present study assumed that the use of WhatsApp as an instructional tool could contribute to vocabulary learning. Following Isisag (2012), the researchers believed that the combination of the media with traditional teaching methods might offer new opportunities to promote the efficacy of foreign language teaching. In the EFL setting of Khorramabad, Iran, where this research was conducted, explicit grammar and intentional vocabulary instructions dominate English classes. That is to say; learners are supposed to memorize the meaning of the words and do different exercises to learn grammar and vocabulary. One reason for such teaching strategies is that in university entrance examinations, students are supposed to be successful in multiple-choice word recognition tests. Therefore, they mostly use memorization as the learning strategy.

Additionally, high school students do not have much opportunity to attend language classes due to the time constraints they experience preparing for the examination. Thus, although research findings mostly support incidental vocabulary learning, the researchers' incentive was to find practical ways to enhance the students' learning conditions. One way was to increase the word encounters via WhatsApp. They compared the effects of two input modalities: visual (reading) and audio (listening) to explore which type of input, combined with traditional classroom practices, could be more effective in enhancing participants' vocabulary knowledge. The researchers considered the interactive environment provided by the application, frequent exposure to language, and the possibility to use mobile phones anytime and anywhere as the opportunities to invest in them. The findings of this study may potentially provide insights into unlocking how the use of social networks can promote students' vocabulary retention. The article provides a literature review followed by the research questions and method of the study. Detailed explanations are given regarding the participants, instruments, and classroom procedures. Researchers' interpretations of the results section are given in the Results section. The conclusion embraces some suggestions for further research and concluding remarks.

Social networking applications are types of internet websites in which individuals, groups, and organizations come together based on prevailing conditions and share their information, subjects, and contexts. Moreover, the use of social networks as an educational method will cause creativity and interpersonal relationship (Swist, Collin, McCormack, \& Third, 2015). The use of social networking in generating online communities is prevalent among L2 practitioners. Teachers create social groups to facilitate interaction with students beyond L2 classrooms (Rashtchi \& Porkar, 2020). As defined by Bryer and Zavatarro (2001), social media are technologies that improve social interaction, make collaboration possible, and enable discussion among learners. Social networks, as a modern tool, can assist L2 teachers and learners in accessing information quickly. Blogs, wikis, media sharing tools, networking platforms, and virtual worlds are some social media types. Their role in language learning has been the focus of some studies. For example, Rashtchi and Hajihassani (2010) showed the benefits of weblogs in improving EFL learners' reading ability. In a qualitative 
study, Selwyn (2009) concluded that Facebook could help university students overcome the challenges they encounter in their academic life. Slim and Hafedh (2019) investigated the impacts of using Facebook on learning English for specific purposes. Although no significant differences were specified in the experimental and control groups' achievements, the researchers found that employing Facebook had resulted in developing a positive attitude among learners.

One of the popular social networks is WhatsApp, which has been used by some researchers for teaching vocabulary (Jafari \& Chalak, 2016; Bensalem, 2018). The researchers of the current study, in line with these researchers, postulated that the use of WhatsApp could be an excellent source for drawing the learners' attention and facilitate learning new words. As Siyanova-Chanturia and Webb (2016) put forth, in EFL contexts, vocabulary learning is a big challenge for learners since instruction is limited to the classroom environment. The use of WhatsApp could be a remedy for learners to have a more frequent encounter with words. The results of previous studies on the decisive role of technology in vocabulary retention (Hermagustiana \& Rusmawaty, 2017; Ma \& Kelly, 2006; Rashtchi \& Aghili, 2014) also stimulated the researchers to examine the efficacy of the social network as a tool for vocabulary learning.

A review of the literature indicates that one of the major concerns of researchers in vocabulary teaching is examining the usefulness of incidental or intentional vocabulary teaching (Restrepo Ramos, 2015). Incidental learning is the result of meaning-focused activities in which learners gain the meaning of the words through reading or listening. However, intentional learning requires learners to focus on learning words and employ different activities "to explicitly focus students on learning words" (Webb, 2020, p.5). Generally speaking, most researchers believe that incidental learning obtained from the focus of attention on language use is a more effective process in vocabulary acquisition (Zimmerman, 2014), and the efficacy of intentional learning is limited (Webb, 2020). However, some researchers argue for the necessity of an explicit focus on vocabulary (Deccarico, 2001). Laufer (2005) emphasizes the importance of intentional vocabulary learning and believes that explicit learning of words contributes to their retention. Webb (2020) maintains that intentional vocabulary learning serves as a basis for future meaning-based vocabulary acquisition.

Furthermore, all SLA researchers have acknowledged the significant role of input in the process of language learning. However, the type and modality of input and conceptualization of how language learners manage data have been the source of much debate (Doughty \& Long, 2003; Ellis, 2008). According to VanPatten (2003), input is the language that a learner "hears or reads" and has "some kind of communicative intent" (p.25). As Schwartz (1993) claimed, to improve the knowledge system of a specific language, the learner must be exposed to instances or exemplars of that particular language. Without this type of exposure, language development will not occur. Thus, input refers to all language samples used to communicate a message (VanPatten \& Leeser, 2006).

Additionally, the role of language input in information processing theories is essential since the frequency of the information embedded in the input helps language learners acquire the target language (Nassaji \& Fotos, 2011). One factor which has received much emphasis in the discussion regarding input is attention. Schmidt (2001) argues that attended learning is far superior, and for all practical purposes, attention is necessary for different aspects of L2 learning. The researchers of the current study assumed that by increasing the exposure of EFL learners via WhatsApp opportunities for learning and retention of vocabulary would increase. Therefore, they proposed the following research questions for a quasi-experimental study with a non-equivalent control group pretestposttest design:

RQ1: Is there a change in the vocabulary knowledge of the group that receives text messages via WhatsApp from pretest to immediate and delayed posttests?

RQ2: Is there a change in the vocabulary knowledge of the group that receives voice messages via WhatsApp from pretest to immediate and delayed posttests?

RQ3: Does the type of teacher-provided input (voice vs. written messages) via WhatsApp have different impacts on EFL learners' vocabulary learning and retention? 


\section{Research Method}

\subsection{Participants}

Fifty school girls aged between 16 and 17 at the intermediate level of language proficiency (B1, according to the Common European Framework of Reference for Languages) took part in this study. The participants, selected based on convenience sampling, were studying in two intact classes in a language institute in Khorramabad, Iran. The results of a general English proficiency test (GPT) revealed that the participants were homogenous, with scores clustering around the mean $( \pm 1 \mathrm{SD}$ above and below the mean). The groups were randomly assigned to the voice message group (VMG) and the text message group (TMG).

\subsection{Instruments}

The researchers employed three instruments for data collection; a general English proficiency test, a vocabulary pretest, and a vocabulary posttest administered twice (as immediate and delayed posttests). A general proficiency test (GPT) in two sections adopted from the Cambridge Preliminary English Test 7 (2012) was employed to explore whether the participants were at the same level of language proficiency at the onset of the study. The reading part of the test consisted of 35 reading questions, and the writing part comprised three parts, which examined a range of writing skills. Questions 1-5 carried one mark each. Item 6 was marked out of five, and items 7 and 8 were marked out of 15 , giving a total of 25 . The allocated time for the test was one hour. The reliability of the test estimated via Cronbach's alpha showed an acceptable index $(r=.893)$. The inter-rater reliability of the writing section computed through Pearson's $r$ showed a high consistency between the two raters $(\mathrm{r}=.843)$.

The second instrument was a 30-item vocabulary achievement test developed by the researchers. The test contained the textbook's new words that the students were going to study during the semester. It could ensure the researchers that the participants were not familiar with the terms before the treatment. Two English language teachers with ten years of experience verified its content validity after some revisions (Appendix A). The test was piloted, and its agreement (Brown, 2005) calculated through Cohen's Kappa coefficient was .569. The researchers developed another 30-item vocabulary test parallel to the pretest. That is, the words were the same as the pretest but appeared in a new context (Appendix B). The purpose of the test was to examine the vocabulary achievement of the participants after the treatment. Two experienced teachers reviewed the test and attested to its content validity. Then the test was piloted, and its agreement using Cohen's Kappa formula revealed an acceptable index $(K=.57)$. The items of the immediate posttest were shuffled for the delayed posttest to control the practice effect. The time allocated for each vocabulary test was 30 minutes. The total number of the target words the participants were supposed to learn was sixty.

\subsection{Piloting Tests}

Before the treatment, the two teacher-made tests (pretest and posttest) were piloted among 25 students bearing almost the same characteristics as the main study participants. Following Brown (2005), for validating the achievement tests, as a criterion- referenced test (CRT), the pilot group was selected from those who knew the words. The reason was to examine whether there were any malfunctioning items. If the students who knew the words could not perform successfully on the test, then the researchers could conclude that the test was not appropriate. The skewness ratios of the pretest and posttest scores were -2.55 and -2.69 (obtained from dividing statistic by standard error), respectively. Since skewness ratios $(-2.55$ and -2.69$)$ exceeded the legitimate range of normal distribution $( \pm 1.96)$, the two sets of scores were not normally distributed, indicating that the testtakers knew the words (Table 1).

Table 1. Descriptive statistics for piloting the vocabulary pretest $\&$ posttest

\begin{tabular}{cccccccc}
\hline & N & Min. & Max. & Mean & SD & Skewness Statistic & Std Error \\
\hline Pretest & 25 & 4.00 & 30.00 & 20.36 & 6.663 & -1.185 & .464 \\
\hline Posttest & 25 & 4.00 & 29.00 & 20.28 & 6.717 & -1.252 & .464 \\
\hline
\end{tabular}




\subsection{Materials}

The coursebook was English-Phil UEE test-prep (Anari \& Ghoreyshi, 2016), usually used for learners who are going to attend the university entrance examination in Iran.

\subsection{Procedure}

The classes took six weeks, each week, two 90-minute sessions, 18 hours in total. GPT was administered to both groups in the first session. After ensuring that all participants had WhatsApp on their mobile phones, the teacher, who was one of the researchers, created a WhatsApp group for each study group and provided explanations regarding the instructional purposes of the social networking group. In the second session, the researchers administered the vocabulary pretest to ensure that the participants did not know the meaning of the target words before the treatment.

\subsection{Voice Message Group (VMG)}

The teacher started the classes by writing the new words of the lesson on the board and providing explanations, synonyms, and antonyms for each item. Then she read the passage while students were engaged in silent reading (the reading while listening process). Meanwhile, the teacher referred to the parts of speech of the words and exemplified each in a few sentences. Afterward, the students completed a worksheet in three sections to practice the new words explicitly. The first section contained some fill-in-the-blanks exercises and matching word lists with their equivalents. In the next section, learners had to write the meaning of the new words in their L1 (Persian) or English. The last part of the worksheets was sentence production with given terms. At the end of the session, the teacher spot-checked the students by asking the meaning of the words. One day after the class, the teacher shared her recorded voice message on the WhatsApp group for five new words. She pronounced the new terms for three times expressively to attract the students' attention. She provided definitions, synonyms, and antonyms for each word. The students were encouraged to listen to the files as many times as they needed to memorize the words. They could ask questions or require further explanations from the teacher or other classmates.

\subsection{Text Message Group (TMG)}

The classroom procedure for this group was the same as VMG. However, instead of sharing voice messages, the teacher sent text messages. She wrote the vocabulary items and highlighted them to make them salient. Also, she provided definitions, synonyms, and antonyms for the words. Similar to the VMG, TMG members were encouraged to memorize the words and their meanings. They could interact with the teacher or peers when they had any queries.

\subsection{Posttest}

After the 12-session treatment, the participants took two vocabulary posttests. The first administration was on the $13^{\text {th }}$ session, and the other was after a two-week interval to examine vocabulary retention.

\section{Findings and Discussion}

Table 2 shows the descriptive statistics obtained from the administration of GPT to the groups. The results show that the mean scores of VMG $(\mathrm{M}=42.3, \mathrm{SD}=2.16)$ and $\mathrm{TMG}(\mathrm{M}=41.5, \mathrm{SD}=2.93)$ were close to each other. The results of the skewness indicated that the distributions of scores in both groups were normal ( 0.95 for VMG and 0.49 for TMG, both ratios falling between \pm 1.96 , obtained from dividing statistic by standard error), and running parametric tests enjoyed legitimacy.

Table 2. Descriptive statistics of GPT scores by groups

\begin{tabular}{cccccccc}
\hline & N & Min. & Max. & Mean & SD & \multicolumn{2}{c}{ Skewness } \\
\cline { 2 - 7 } & Statistic & Statistic & Statistic & Statistic & Statistic & Statistic & Std. Error \\
\hline TMG & 25 & 36.00 & 48.00 & 41.5600 & 2.93442 & .231 & .464 \\
VMG & 25 & 37.00 & 46.00 & 42.3000 & 2.16025 & -.441 & .464 \\
Valid N (listwise) & 25 & & & & & & \\
\hline
\end{tabular}


The Levene's $\mathrm{F}=2.378, p>.05$ ) indicated that the assumption of the homogeneity of variances was assumed. The results of the independent samples t-test showed that there was no statistically significant difference between the means of the groups, $\mathrm{t}(48)=1.01, \mathrm{p}>0.05$. Thus, the researchers concluded that the participants in the two groups shared the same level of language proficiency and were homogenous.

Table 3 shows the descriptive statistics obtained from the administration of the pretest and the immediate and delayed posttests.

Table 3. Descriptive statistics vocabulary pretest

\begin{tabular}{lccccc}
\hline & & Min. & Max. & Mean & SD \\
\hline Pretest & TMG & 2.00 & 14.00 & 6.24 & 2.79 \\
& VMG & 2.00 & 15.00 & 7.08 & 2.52 \\
\multirow{3}{*}{ Immediate Posttest } & Total & 2.00 & 15.00 & 6.66 & 2.66 \\
& TMG & 11.00 & 30.00 & 22.88 & 4.76 \\
& VMG & 12.00 & 30.00 & 23.04 & 4.83 \\
Delayed Posttest & Total & 11.00 & 30.00 & 22.96 & 4.75 \\
& TMG & 13.00 & 30.00 & 22.20 & 4.12 \\
& VMG & 15.00 & 30.00 & 22.36 & 4.42 \\
& Total & 13.00 & 30.00 & 22.28 & 4.23 \\
\hline
\end{tabular}

The Kolmogorov-Smirnov test was conducted to examine the normality of the distribution of the scores in the three vocabulary tests. The $\mathrm{p}$ values larger than .05 indicated normality $(p>.05)$; however, since some of the $\mathrm{p}$ values were smaller than .05 , the researchers had to use nonparametric tests.

Two non-parametric tests of Friedman repeated measures ANOVA were performed to compare the performances of the TMG and VMG from time 1 (pretest) to time 2 (immediate posttest) and time 3 (delayed posttest) to answer the first and second research questions. Table 7 shows the results of the test $\left(\chi^{2}(2,24)=39.4, p<.001\right)$ for TMG. As the results of the p-value indicate, there is a significant difference between the performances of TMG in the pretest, immediate posttest, and delayed posttest.

Table 4. TMG Friedman test, pretest, immediate, \& delayed posttests

\begin{tabular}{cc}
\hline $\mathrm{N}$ & 25 \\
\hline Chi-Square & 39.402 \\
$\mathrm{df}$ & 2 \\
Asymp. Sig. & .000 \\
\hline
\end{tabular}

In the next step, Wilcoxon tests were run to help the researchers locate where the difference(s) lay. The results of the Wilcoxon test indicated that the difference between the posttests and the pretest scores was statistically significant (mean rank of 0.00 versus $25.5, \mathrm{Z}=6.16, p<.001$ ). In contrast, the difference between the delayed posttest and the immediate posttest scores (mean rank of 21.35 versus $22.15, \mathrm{Z}=.73, \mathrm{p}>.05$ ) was not significant. This finding indicates that the participants were successful in vocabulary retention and had not forgotten the words from the immediate posttest to the delayed posttest. The effect size obtained from dividing $\mathrm{Z}$ by the square root of cases $(25 \times 3)$ is 0.7 , which using Cohen's (1988) criteria, indicates a large effect size indicating that 7 percent of the change in the dependent variable was due to the treatment.

Friedman repeated-measures ANOVA was performed to examine the effectiveness of the voice messages on the participants' vocabulary learning and retention. As the results of the test $\left(\chi^{2}(2,24)\right.$ $=41.583, p<.001$ ) indicate (Table 5), there is a statistically significant difference between the performances of VMG in the pretest, immediate posttest, and delayed posttest. 
Table 5. VMG Friedman test, pretest, immediate, \& delayed posttests

\begin{tabular}{cc}
\hline $\mathrm{N}$ & $\mathbf{2 5}$ \\
\hline Chi-Square & 41.583 \\
$\mathrm{df}$ & 2 \\
Asymp. Sig. & .000 \\
\hline
\end{tabular}

Two Wilcoxon tests were conducted to examine where exactly the differences suggested by Friedman test occurred. Table 6 shows the ranks of the scores in each test.

Table 6. Ranks statistics of Wilcoxon test, VMG

\begin{tabular}{llccc}
\hline & & N & Mean Rank & Sum of Ranks \\
\hline Immediate posttest \&Pretest & Negative Ranks & $0^{\mathrm{a}}$ & .000 & .000 \\
& Positive Ranks & $25^{\mathrm{b}}$ & 13.00 & 325.00 \\
& Ties & $0^{\mathrm{c}}$ & & \\
& Total & 25 & & 174.50 \\
& Negative Ranks & $16^{\mathrm{d}}$ & 10.91 & 56.50 \\
& Positive Ranks & $5^{\mathrm{e}}$ & 11.30 & \\
& Ties & $4^{\mathrm{f}}$ & & \\
& Total & 25 & & \\
\hline
\end{tabular}

As the results of the Wilcoxon test showed, the immediate posttest results were significantly different from the pretest (mean rank of 0.00 versus $13.0, \mathrm{Z}=4.38, p<.001$ ); and the delayed posttest scores were significantly different from the posttest scores (mean rank of 11.3 versus 10.91 , $\mathrm{Z}=2.73, p<.05)$. The lack of a statistically significant difference between the immediate and delayed posttests shows that the participants in VMG could remember the words they had learned. The effect size ( $r=.5$.), using Cohen's (1988) criteria, indicates a large effect size.

Quade's Rank Analysis of Covariance was conducted to explore further the difference between the effects of the two treatments. To do so, first, both immediate posttest and delayed posttest scores of the participants were ranked. Then, a linear regression of the ranks was performed, and the residuals were saved. Table 7 shows the descriptive statistics of the residuals for delayed posttest scores from immediate posttest scores.

Table 7. Residual statistics, delayed posttest scores from immediate posttest scores

\begin{tabular}{lccccc}
\hline & Min. & Max. & Mean & SD & N \\
\hline Predicted value & 12.2381 & 28.1910 & 22.2800 & 3.98887 & 50 \\
Residual & -3.15321 & 2.52604 & .00000 & 1.41736 & 50 \\
Std. predicted value & -2.517 & 1.482 & .000 & 1.000 & 50 \\
Std. residual & -2.202 & 1.764 & .000 & .990 & 50 \\
\hline
\end{tabular}

Finally, a Mann-Whitney U test was run to probe the difference between the ranks of the two groups. As the results indicated, there were no statistically significant differences between the two groups $(\mathrm{U}=.309, p>.05)$ regarding their ranks in the delayed posttests compared to the immediate posttests. In other words, the results of the test showed that while the two groups were successful in learning the words and remembering them, the type of input did not cause any statistically significant differences between the groups. 


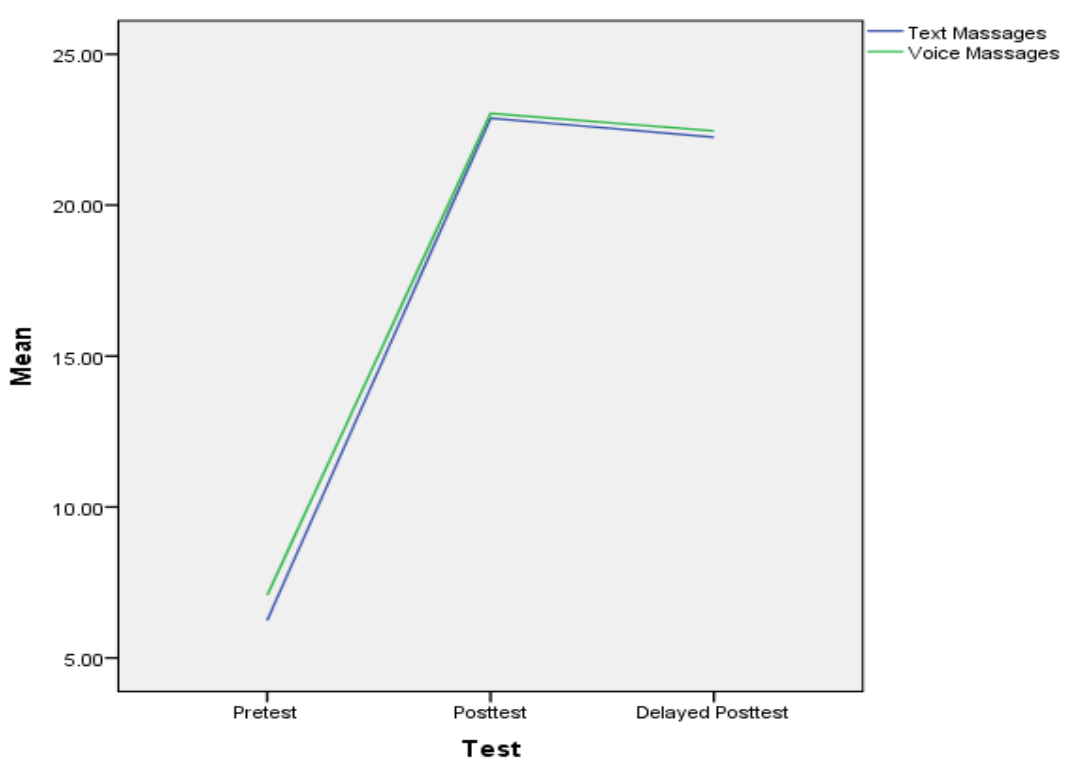

Fig. 1. Line graph of two groups' progress in three tests

The affirmative answers to the first and second research questions showed that intentional vocabulary learning strategies via WhatsApp were useful for learning and retaining new words. However, the type of input (voice vs. text messaging), as proposed by the third research question, did not cause any statistically significant differences between the groups. The study showed that activities related to intentional vocabulary learning and memorization could help learners have mental access to the delayed posttest words. As Barcroft (2015) argues, focus on learning vocabulary and disregarding other language-related activities can be the key to the efficacy of intentional learning. Besides, in intentional learning, learners voluntarily use all possible techniques and strategies they have developed during their schooling to overcome the barriers which impede their success. Likewise, it can be assumed that the WhatsApp messages allowed the learners to employ their preferred strategies for vocabulary learning, as the participants tried to learn individually and at their own pace. As Nation (2013) puts forth, a considerable proportion of vocabulary learning relies on using appropriate strategies. Regarding the present study, motivation and desire to learn were additional factors that affected the results since the participants were getting ready to take the university entrance examination.

Another reason for the efficacy of intentional vocabulary learning was that WhatsApp increased the frequency of exposure to the new words (Pellicer-Sánchez, 2020). Peters (2014) found that repeated exposure could have a significant impact on vocabulary learning. Also, the finding by Alali and Schmitt (2012) lends some support to the role of repetition in vocabulary learning. The researchers assume that the reiteration of the words in the messages that the students received after explicit class instruction could have a vital role in learning and remembering vocabulary. Also, the ubiquitous learning provided by mobile phones could have a decisive role in learning the words.

An alternative possibility for the success of the participants could be the integration of two modes of learning. During the treatment, the conventional in-class learning in which learners were engaged mostly in paper and pencil activities followed by out-of-class technology-based learning put a less cognitive load on their working memory (Baddeley,1997). That is to say, the combination of exercises that required production (i.e., doing worksheets and answering to teacher's questions), and receptive activities (i.e., listening to or reading messages in WhatsApp group) could lead to better results in vocabulary learning. 
The findings emphasize the role of social networking in vocabulary learning. Using such tools is mainly useful in EFL settings where learners do not have adequate opportunities to encounter the target language. Receiving messages from the teacher via WhatsApp could give the learners the advantage of regulating their study time according to their schedule. Also, individualized learning inherent in the use of mobile phones for educational purposes frees the participants from the pressure of keeping pace with the class, which itself can impede learning (Rashtchi \& Tollabi Mazraehno, 2019; Tanner \& London, 2009). Employing the strategies that were compatible with their personality characteristics and learning styles could be another reason for the participants' success in vocabulary learning. Placing the burden of learning on the shoulders of the participants can trigger their sense of responsibility and foster autonomous learning.

The amount of mental processing involved in the learning of the words can also be another explanation for the findings. The classroom practices, along with the presentation of words via WhatsApp, could bring about a deep mental involvement that is assumed to be effective in increasing the learners' attention to the words (Nation, 2013). In the same vein, Godfroid, Boers, and Housen (2013) maintain that giving some attention can lead to long-term memory storage. This conclusion can find support from the noticing hypothesis proposed by Alali and Schmidt (2012). This study revealed that English teachers could benefit from social networking, such as WhatsApp, via mobile phones to teach vocabulary to EFL learners since they are easy to use and preferred by many learners. The findings showed that WhatsApp could encourage students to learn vocabulary since it has the advantage of extending learning to outside classroom settings. It can also connect students with the teacher and other classmates at any time and in any place. The present study signifies the importance of looking for more attractive ways of providing input for EFL learners.

\section{Conclusion}

The study showed that WhatsApp could help develop EFL learners' vocabulary knowledge and have a lasting impact on remembering the words they have learned. Besides, the type of input that the learners receive, the attraction adolescents have toward using mobiles and social networking could have an impact on increasing their motivation for learning vocabulary. The tendency of learners to use mobile phones regularly during their daily-life activities, if used for learning purposes, can increase the frequency of exposure required for vocabulary learning. The study results can encourage teachers to consider the use of social networking platforms and applications as a possibility for increasing the learners' encounter with language in EFL settings. Material developers can draw on the results of this study to make informed decisions on how to adopt technology in teaching vocabulary in different courses. However, the use of social networking for language teaching still needs further investigations, particularly concerning productive language skills. One limitation of the present study was that the participants were limited to girls. Therefore, the results should be generalized to both genders cautiously. This study was also limited in considering the participants' preferences and personality factors. Further studies may consider learner characteristics as a variable to investigate in the domain of vocabulary learning integrated with social media. Additionally, interested researchers may explore the participants' perceptions regarding the use of social media for vocabulary learning.

\section{References}

Alali, F. A., \& Schmitt, N. (2012). Teaching formulaic sequences: The same as or different from teaching single words? TESOL Journal, 3(2), 153-180. https://doi.org/110.1002/tesj.13

Anari, S., \& Ghoreyshi, S.M. (2016). English-Phil UEE test-prep. Tehran: Mobtakeran.

Atkinson, R. K. (2005). Multimedia learning in mathematics. In R. E. Mayer (Ed.), Cambridge Handbook of Multimedia Learning (pp. 393-408). New York, NY: Cambridge University Press.

Baddeley, A. D. (1997). Human Memory: Theory and Practice, East Sussex: Psychology Press.

Baddeley, A. D. (1986). Working Memory. Oxford: Clarendon Press.

Baddeley, A. D. (1992). Working Memory. Science, 25(5), 556-559. https://doi.org/10.1126/science.1736359. 
Baddeley, A. D., \& Hitch, G. J. (1974). Working memory. In G. H. Bower (Ed.), The Psychology of Learning and Motivation: Advances in Research and Theory (pp. 47-89). New York, NY: Academic Press.

Barcroft, J. (2015). Lexical Input Processing and Vocabulary Learning. Amsterdam: John Benjamins.

Bensalem, E. (2018). The impact of WhatsApp on EFL students' vocabulary learning. Arab World English Journal (AWEJ), 9 (1), 23-38. https://dx.doi.org/10.24093/awej/vol9no1.2

Blake, R. (2008). Brave New Digital Classroom: Technology and Foreign Language Learning. Washington, DC: Georgetown University Press.

Brown, J. D. (2005). Testing in Language Programs. New York, NY: McGraw-Hill.

Bryer, T., \& Zavattaro, S. (2011). Social media and public administration Administrative Theory \& Praxis, 33(3), 325-340. https://doi.org/10.2753/ATP1084-1806330301

Cambridge Preliminary English Test 7 Student's Book (2012). Cambridge: Cambridge University Press.

Cohen, D. A., \& Weaver, J. S. (2005). Styles and strategies-based instruction: A teachers' guide. University of Minnesota CARLA Working Paper Series A rewritten version of Paper \#7 Center for Advanced Research on Language. Computing Research, 29(3), 297-313.

Cohen, J.W. (1988). Statistical Power Analysis for the Behavioral Sciences (2nd ed). Hillsdale, NJ: Lawrence Erlbaum.

Craik, F. I. M., \& Lockhart, R. S. (1972). Levels of processing: A framework for memory research. Journal of Virtual Learning and Verbal Behavior, 11 (6), 671-684. https://10.1016/S0022-5371(72)80001-X

Decarrico, J. S. (2001). Vocabulary learning and teaching. In M. Celce-Murcia (Ed.), Teaching English as a Second or Foreign Language (pp. 285-299). Boston, MA: Heinle \& Heinle.

Doughty, C. J., \& Long, M. H. (2003). Optimal psycholinguistic environments for distance foreign language learning. Language Learning \& Technology, 7(3), 50-80.

Ellis, N. (2008). Usage-based and form-focused language acquisition: The associate learning of constructions, learned attention, and limited L2 end state. In P. Robinson \& N. Ellis (Eds.), Handbook of Cognitive Linguistics and Second Language Acquisition (pp. 372-405). New York, NY: Routledge.

Godfroid, A., Boers, F., \& Housen, A. (2013). An eye for word: Gauging the role of attention in incidental L2 vocabulary acquisition by means of eye-tracking. Studies in Second Language Acquisition, 35(4), 483-517. https://doi.org/10.1017/S0272263113000119

Ma, Q., \& Kelly, P. (2006). Computer assisted vocabulary learning: Design and evaluation. Computer Assisted Language Learning, 19 (1), 15-45. https://doi.org/110.1080/09588220600803998

Hermagustiana, I., \& Rusmawaty, D. (2017). The use of technology for vocabulary instruction in EFL classrooms: Support and challenges. Advances in Intelligent Systems Research (AISR), 144. 137-143. Retrieved from https://download.atlantis-press.com/article/25902606.pdf

Isisag, K. U. (2012). The positive effects of integrating ICT in foreign language teaching. International Conference "ICT for language learning." Retrieved from www://conference. pixel-online.net/

Jafari, S., \& Chalak, A. (2016). The role of WhatsApp in teaching vocabulary to Iranian EFL learners at junior high school. English Language Teaching, 9 (8), 85-92. http://dx.doi.org/10.5539/elt.v9n8p85

Laufer, B. (2005). Focus on form in second language vocabulary learning. In S. H. Foster-Cohen, M. GarciaMayo, \& J. Cenoz (Eds.), EUROSLA Yearbook (Vol. 5, pp. 223-250). Amsterdam: John Benjamins.

Mayer, R. E. (2009). Multimedia Learning ( $\left.2^{\text {nd }} e d\right)$. New York, NY: Cambridge University Press.

Nassaji, H., \& Fotos, S. S. (2011). Teaching grammar in second language classrooms: Integrating formfocused instruction in communicative context. New York: Routledge.

Nation, P. (2013). Vocabulary learning and teaching. In P. Robinson (Ed.), The Routledge Encyclopedia of Second Language Acquisition (pp. 682-686). New York, NY: Routledge.

Nation, P. \& Gu, P. Y. (2007). Focus on Vocabulary. Sydney: NCELTR, Macquarie University. 
Paas, F., van Gog, T., \& Sweller, J. (2010). Cognitive load theory: New conceptualizations, specifications, and integrated research perspectives. Educational Psychology Review, 22(2), 115-121. https://doi.org/10.1007/s10648-010-9133-8

Pellicer-Sánchez, A. (2020). Learning single words vs. multiword items. In S. Webb (Ed.). The Routledge Handbook of Vocabulary Studies (pp.158-173). Oxon: Routledge.

Peters, E. (2014). Factors affecting the learning of single-word items. In S. Webb (Ed.). The Routledge Handbook of Vocabulary Studies (pp. 125-142). Oxon: Routledge.

Pyc, M.A. \& Rawson, K.A. (2009). Testing the retrieval hypothesis: Does greater difficulty correctly recalling information lead to higher levels of memory? Journal of Memory and Language, 60 (4) 43747. https://doi.org/10.1016/j.jml.2009.01.004

Rashtchi, M., \& Aghili, H. (2014). Computerized input enhancement versus computer-assisted glosses: Do they affect vocabulary recall and retention? Theory and Practice in Language Studies, 4(8), 1665-1674. https://doi.org/10.4304/tpls.4.8.1665-1674

Rashtchi, M., \& Hajihassani, H. (2010). Blog-assisted language learning: A possibility in teaching reading to Iranian EFL learners. International Journal of Language Studies (IJLS), 4(4), 245-262. http://www.ijls.net

Rashtchi, M., \& Porkar, R. (2020). Brainstorming revisited: Does technology facilitate argumentative essay writing? Language Teaching Research Quarterly, 18, 40-52. https://doi.org/10.32038/ltrq.2020.18.03

Rashtchi, M., \& Tollabi Mazraehno, M. R. (2019). Exploring Iranian EFL learners' listening skills via TED talks: Does medium make a difference? Journal of Language and Education, 5(4), 81-97. https://doi.org/10.17323/jle.2019.9691

Restrepo Ramos, F. D. (2015). Incidental vocabulary learning in second language acquisition: A literature review. PROFILE, 17 (1), 157-166. http://dx.doi.org/10.15446/profile.v17n1.43957

Schwartz, B. (1993). On explicit and negative data effecting and affecting competence and linguistic behavior. Studies in Second Language Acquisition, 15(2), 147-163. https://doi.org/10.1017/S0272263100011931

Selwyn, N. (2009). Faceworking: Exploring students' education-related use of Facebook in learning. Media and Technology, 34 (2),157-74. https://doi.org/10.1080/17439880902923622

Siyanova-Chanturia, A., \& Webb, S. (2016). Teaching vocabulary in EFL context. In W.A. Renandya \& H.P. Widodo (Eds.), English Language Teaching Today (pp.227-239). Basel: Springer. https://doi.org/10.1007/978-3-319-38834-2_16

Schmidt, R. (2001). Attention. In P. Robinson (Ed.), Cognition and Second Language Instruction (pp. 3-32). Cambridge: Cambridge University Press.

Slim, H., \& Hafedh, M. (2019). Social media impact on language learning for specific purposes: A study in English for business administration. Teaching English with Technology, 19(1), 56-71. http://www.tewtjournal.org

Sweller, J., \& Chandler, P. (1994). Why some material is difficult to learn. Cognition and Instruction, 12 (3), 185-233. https://doi.org/10.1207/s1532690xci1203_1

Swist, T., Collin, P., McCormack, J., \& Third, A. (2015). Social media and the wellbeing of children and young adults: A literature review. The Commissioner for Children and Young People, Western Australia. https://doi.org/10.13140/RG.2.1.3296.6885.

Tanner, M. W., \& Landon, M. M. (2009). The effects of computer-assisted pronunciation readings on ESL learners' use of pausing, stress, intonation, and overall comprehensibility. Language Learning \& Technology, 13 (3), 51-65. https://www.lltjournal.org/

VanPatten, B. (2003). From Input to Output: A Teacher's Guide to Second Language Acquisition. Boston, MA: McGraw Hill. 
Vanpatten, B., \& Leeser, M. (2006). Theoretical and research considerations underlying classroom practice: The fundamental role of input. In M. R. Salaberry (Ed.), The Art of Teaching Spanish: Second Language Acquisition from Research to Praxis (pp. 55-77). Washington, DC: Georgetown University Press.

Webb, S. (2020). Incidental vocabulary learning. In S. Webb (Ed.). The Routledge Handbook of Vocabulary Studies (pp. 225-239). Oxon: Routledge.

Zimmerman, C. B. (2014). Teaching and learning vocabulary for second language learners. In M. CelceMurcia, D. M. Brinton, \& M. A. Snow (Eds.), Teaching English as a Second or Foreign Language (288302). Boston, MA: National Geographic Learning. 


\section{Appendix A Vocabulary Pretest}

1. Do you think I made a good impression on your parents? "Impression" means .......

1 result

2 effect

3 support

4 habit

2. You should have goals, or else you will be disappointed.

1 achievable

2 readable

agreeable

advisable

3. A group of people having the same religion, job, etc. Are a .......

1 category 2 community $\quad 3$ government 4 missionary

4. The time between the final exam and telling the result of students is a period of real ..... for most students.
1 comfort
2 suffering
3 enjoyment
4 involvement

5. Tom has invited all of us to dinner tonight because of his recent ...... at work.

1 promotion

2 result

3 posture

conclusion

6. Jane has just been which means a company car and an extra five thousand pounds.

1 earned

2 promoted

3 explored

proposed

7. The project will be a success if we can only get the to put it into action.

1 finance 2 entrance $\quad 3$ realization 4 procedure

8. The government should act quickly to help people in ....... .
1 poverty
2 struggle
3 extinction
region

9. They say that they should spend as much money as needed to improve the country's telephone ....

1 device 2 region $\quad 3$ procedure 4 network

10. My parents will ...... my mail to Italy while I am teaching there.

1 forward

2 provide

3 operate

recall

11. The managers have .. a number of circumstances to the agreement.

1 combined

2 restated

3 arranged

4 attached

12. We were glad to see that the of more wood to the fire made it brighter and warmer
addition
2 formation
3 pollution
4 location

13. I haven't been to China , but I have read a lot of books about its culture and people.

1 entirely

2 personally

3 immediately

internationally

14. You should prepare all your carefully before applying for a passport.

1 comments 2 documents 3 occasions .. them any longer.

15. I asked the children to slow down because I was not able to

1 call out to 2 make up with $\quad 3$ keep up with

16. The traffic was too heavy as it was raining hard, so we reached the two hours late.

destination

expectation

3 occasion

17. Mr. Alavi is interested in Asian countries, so he went on a long journey of .......into China.

1 prediction

2 destination

3 exploration

18. Mary was not in a good mood, so she welcomed her guests with a (n)..... smile on her face.

1 brilliant

2 primary

3 artificial

4 effective

19. Wet weather is a of life in many countries of the world like Scotland.

1 period

2. manner

3 feature

sample 
20. Mr. Karimi has always been dreaming of traveling to ....... lands, particularly the ones in South America.
1 global
2 complex
3 flexible
4 distant

21. Dr. Javadi is a of this kind of operation human heart in the world.
1 layer
2 winner
3 gesture

4 pioneer

22. I worry about the

effect that violent films may have on children.

1 destructive

2 repetitive

3 irrelevant

by going to he cinema every afternoon.

23. Bill escaped from
2 reality
3 certainly

24. Trying to ........ the weather is not an easy job, as it requires specialized equipment.
1 estimate
2 mention
3 forecast

25 . We were late getting to the airport, but ..... for us; the plane was delayed.
1 luckily
2 basically
3 certainly

26. I would like to know how Helen manages to keep .... before examinations.
1 firm
2 calm
3 similar
27. As a student he lived very ......, rarely going out and buying very few clothes.
1 economically
2 scientifically
3 necessarily

4 nervous

28. The village was a scene of immense peace, far ..... from the tensions of city life.
1 bothered
2 removed
3 stretched

cold.

29. I would prefer not to travel to a country like Canada in winter because it gets
1 previously
2 necessarily
3 extremely

30. The government has several plans to remove ........ and raise living standards.
1 reality
2 capacity
3 charity

4 capacity

4 express

4 entirely

4 natural

4 emotionally

4 anxiously

4 poverty

\section{Appendix B \\ Vocabulary Immediate and Delayed Posttests}

1. Mary was chosen for the job because she was ..... to the others.
1 conscious
2 voluntary
3 fashionable

2. Our schools should ...... more time to scientific subjects.

1 raise $\quad 2$ devote 3 transfer

3. I can say with ...... that there will be no more discussion today.
1 capacity
2 experience
3 certainty

4. A person who goes to another country to teach people about religion is called a ......
1 teacher
2 missionary
3 passenger

5. These days the business has got into ...... difficulties.
1 financial
2 flexible
3 emotional

6. We don't exactly know what happened; Bill only gave a /an ...... of the events.
1 mistake
2 density
3 outline

7. Many adults seem to know little about some of the most ...... sciences.
1 emotional

8 . I try to .......... two hours every night to my school work.
1 estimate
2 devote
3 spend

9. You can buy a / an ....... version of the dictionary and save money in this way.
1 regular

10. I don't like seeing animals in a zoo. I prefer to see them in their natural ..... areas.
1 relaxed
2 surrounding
3 contrasting

11. Our luggage was checked through to our final ..... .
1 situation
2 destination
3 observation

3 extinction

1 destination
13. My parents will ....... my mails to china while I am working there.

teach our .........
1 stick
2 forward
3 compose to our Tokyo branch next month.
mention
14. John doesn't seem to be happy that he is 3 transferring

superior

4 express

4 impression

4 psychologist

4 facial

4 article

4 repetitive

4 enhance

4 reasonable

individual

connection

inaction 2 hiring

devoting

15. We were waiting ...... for my father coming back from Mecca. 


\section{Smoothly \\ 2 anxiously}

16. Will you quickly

1 update

me on what has been happening.

2 include

3 personally

necessarily

17. I think we started our business with each other

1 exactly

2 recently

3 promise

two years ago.

18. The pilot ........ the plane safely, but there was a crash afterward.
1 landed
2 located
3 reacted

19. A: "How many scientists took part in the conference?"

B: "....... 50 ones."
1 Mostly
2 Nearly
3 Primarily in a few minutes.

20. I think the plane is

1 turning on

2 making up

3 turning up

21. Each school's central ........ should be to teach reading, writing, and arithmetic.

1 mission

2 occasion

3 expression all night because of the wind.

22. The window were

2 suffering

in the north of our city.

23. Most high buildings are

2 interested

3 wrestling

attached

entered

24. It is

located

know

serious

2 average

25 . We need to make changes in the ...... for collecting taxes.

1 practice

2 involvement

3 mechanism

common

efficient

26. The pilot of the airplane had to make a/an landing because of the terrible weather.

1 mystery 2 emergency 3 strategy.

27. Every packet of cigarettes should come with a government health warning which is

4 density to it.

1 attached

2 forced

3 forbidden to friends and family.

28. As I know, Sally had sold only twelve pictures

3 mostly

4 promised

1 recently

2 formally by our bodies; we get them from what we eat or drink.

29. Vitamins cannot be

2 manufactured

3 concentrated

involved 30. Experts ...... that, on average, the world loses a language every two weeks.

1 annoy

2 explore

3 estimate

measure 